\title{
Comparative Study on the Discoloration of Three Types of Heat-Curing Resin Bases
}

\author{
Seong-Hyuk Bang ${ }^{1}$, So-Min Kim ${ }^{2}$ \\ ${ }^{1}$ Best Dental Laboratory, Seoul, ${ }^{2}$ Department of Dental Technology and Science, Shinhan University, Uijeongbu, Korea
}

Objective: This study intended to evaluate how 3 types of resins, by name Paladent 20 (Heraeus Group, Hanau, Germany), SR Triplex Hot (Ivoclar Vivadent Inc., Schaan, Liechtenstein), and QC-20 (Dentsply Sirona, York, PA, USA), commonly used as denture materials in the clinical field were influenced by edible materials such as coffee and black tea.

Methods: Three experimental specimens were prepared for each type of resin and were used in measuring their color changes with a spectrophotometer. After depositing a specimen for each type of resin in 3 sample solutions (coffee, black tea, and distilled water) contained in 3 separate beakers, the color change in each specimen was measured on 1, 5, 10, and 15 days. The $L^{*}$ value, $\mathrm{a}^{*}$ value, and $\mathrm{b}^{*}$ value were measured, and the $\Delta \mathrm{E}^{*}$ value was calculated for each specimen.

Results: Each type of resin showed differences in color change over time $(p=0.004)$, but did not display color change depending on the different solutions $(p=0.920)$. The QC-20 and the SR Triplex Hot showed comparable color stabilization and exhibited the same degree of color stabilization as that of the general curing resin. Paladent 20 demonstrated somewhat poorer color stabilization in the black tea solution. For the full dentures, any spot with insufficient polishing showed poor discoloration.

Conclusion: Paladent 20 appears to be more discolored than the other resins when exposed to black tea solution. Hence, patients with dentures made of Paladent 20 should not be recommended to drink black tea habitually.

Keywords: tooth discoloration, dentures, heat-curing resin

\section{Introduction}

The number of patients wearing dentures has greatly increased in recent years due to the increase in the number of elderly people and the insurance policy related to dentures. The demand for removable dentures is high for patients who are unable to

\section{Corresponding author So-Min Kim}

E-mail: ksm13501@shinhan.ac.kr

(iD) https://orcid.org/0000-0003-1385-0322

Received December 1, 2021, Revised December 18, 2021, Accepted December 25, 2021 receive implants due to the high cost of the appliance, systemic disease, etc. Thus, removable dentures play a crucial role in dental filling.

Since the introduction of poly (methyl methacrylate) (PMMA) in 1937 , acrylic resin has been the most frequently used material for dentures to date $[1,2]$. The clinical role of denture resin is to have biocompatibility and appropriate solidity and to fix and maintain artificial teeth. Therefore, the resin should exist in harmony with the soft tissues within the oral cavity and have structural and chemical stability. The ideal denture resin should be transparent and maintain its color when clinically applied, and its transparency and color should not change during curing [3]. Acrylic resin is suitable for denture material because of its su-

Copyright (C) 2021. Korean Academy of Preventive Dentistry.

This is an Open Access article distributed under the terms of the Creative Commons Attribution Non-Commercial License (http://creativecommons.org/licenses/ by-nc/4.0) which permits unrestricted non-commercial use, distribution, and reproduction in any medium, provided the original work is properly cited. 
periority in aesthetic aspects, lightness, and ease of processibility. PMMA is usually available in the form of gel, power, or liquid. The powder is composed of polymerization initiator, pre-polymerized acrylic polymer powder (beads), red fiber to reproduce the microvessels of pigment and gum, and strengthener. The liquid is composed of methyl methacrylate, plasticizer, crosslinking bonding agent, polymerization promoter, etc. [2,4].

Owing to the increase in the aesthetic aspects in the dental field, studies on color stability of the dental material have been actively conducted, and there has been increasing interest in the color stability of the denture resin. As part of the studies on denture resin, Asmussen [5,6] studied the effect of resin components on color change. Buyukyilmaz et al. [7] reported that heat-curing denture resin is relatively superior to autopolymerized resin in color stability. Wozniak et al. [8] documented color change of the denture resin resulting from denture cleansing agent and saliva.

This experiment compares the advantages and disadvantages of the material characteristics of each material by evaluating how coffee and black tea-which Koreans frequently drinkand distilled water, as the control group, affect color change of Paladent 20 (Heraeus Group, Hanau, Germany), SR Triplex Hot (Ivoclar Vivadent Inc., Schaan, Liechtenstein), and QC-20 (Dentsply Sirona, York, PA, USA) denture resins. These are the 3 most frequently used materials currently, and this study informs the preparation of standards for clinical application.

\section{Materials and Methods}

\section{Materials}

Three of the most frequently used types of heat-curing denture base resins consisting of PMMA were selected and tested (Table 1).

As experimental equipment, the water purification system, PURELAB Flex3 (ELGA LabWater, USA), was used to prepare the solutions and distilled water. The spectrophotometer, SP 62 PURELAB Flex3 (X-RITE, Grand Rapids, MI, USA), was used to measure the color change, and OVEN LB30575054 (Thermo Fisher Scientific, Dreieich, Germany) was used to store the specimens at a constant temperature. Coffee and black

Table 1. Heat-curing resin bases

\begin{tabular}{lccl}
\hline \multicolumn{1}{c}{ Product } & Key ingredient & Manufacturer & \multicolumn{1}{c}{ Country } \\
\hline Paladent 20 & PMMA & Heraeus & Germany \\
SR Triplex Hot & PMMA & Ivoclar & Liechtenstein \\
QC-20 & PMMA & Dentsply & USA \\
\hline
\end{tabular}

PMMA: poly (methyl methacrylate). tea-which Koreans frequently drink —and distilled water, which served as the control group, were used (Table 2).

\section{Methods}

A total of 30 experimental specimens for examination with the naked eye were made, 10 full dentures each (Table 3 ).

\section{1) Producing full dentures}

A total of 30 anhydrite (GC FUJIROCK ${ }^{\circledR}$ EP, Tokyo, GC) denture working molds were made using the standard silicon mold (U-402, Nissin Dental Products, Inc., Kyoto, Japan) of maxillary edentulous impression. Wax trial dentures were made of base plate wax using the general method of making working molds, and resin artificial teeth (Trubyte Biotone ${ }^{\circledR}$, Dentsply Sirona, York, PA, USA) were arranged. At this point, 264 was used for the anterior tooth and M32 (SHOFU INC., Kyoto, Japan) for the molar teeth. The impression was acquired again using putty rubber impression (GC Exafine Putty, Tokyo, GC) to produce a mold for replicating the dentures. By implanting the same artificial tooth in the tooth position of the mold and fitting it into the working mold, a wax trial denture with the same thickness and teeth arrangement was made after infusing base plate wax. Plaster and Platinum 95 (Zhermack, Marl, Germany) were used for burying, curing was done as per the manufacturer's manual after flasking (Table 4), and finally, high polishing was performed.

\section{2) Color measurement}

Dentures that were stored in distilled water for 24 hours were cleansed and dried for color testing using the spectrophotometer (SP 62 PURELAB Flex3, X-RITE). The color tone was measured and recorded before coloration. For the sample solutions, $8 \mathrm{~g}$ of coffee powder and black tea were mixed with $400 \mathrm{ml}$ of distilled water each, and undiluted distilled water

Table 2. Solutes and solutions

\begin{tabular}{llcc}
\hline & \multicolumn{1}{c}{ Product } & Manufacturer & Country \\
\hline Coffee & Moca mild gold & Maxim & Korea \\
Black tea & Yellow label tea & Lipton & UK \\
Distilled water & Manufactured with ultrapure water manufacturing device \\
\hline
\end{tabular}

Table 3. Classification of each specimen in the experiment

\begin{tabular}{lc}
\hline Product & Total denture \\
\hline Paladent 20 & 10 \\
SR Triplex Hot & 10 \\
QC-20 & 10 \\
\hline
\end{tabular}

Values are presented as number. 
Table 4. Polymerization procedure

\begin{tabular}{lcc}
\hline Product & Power/Liquid ratio & Polymerization procedure \\
\hline Paladent 20 & $20 \mathrm{~g}: 8 \mathrm{ml}$ & $80^{\circ} \mathrm{C}: 15$ minutes $\rightarrow 100^{\circ} \mathrm{C}: 30$ minutes \\
SR Triplex Hot & $23.4 \mathrm{~g}: 10 \mathrm{ml}$ & $100^{\circ} \mathrm{C}: 45$ minutes \\
QC-20 & $23 \mathrm{~g}: 10 \mathrm{ml}$ & $100^{\circ} \mathrm{C}: 20$ minutes \\
\hline
\end{tabular}

Table 5. Denture base resins at each time point in deionized water $(n=10)$

\begin{tabular}{lcccc}
\hline & Day 0 & Day 5 & Day 10 & Day 15 \\
\hline Paladent 20 & 0.00 & 0.45 & 0.51 & 0.42 \\
SR Triplex Hot & 0.00 & 0.32 & 0.27 & 0.29 \\
QC-20 & 0.00 & 0.66 & 0.48 & 0.48
\end{tabular}

Values are presented as mean color differences $\left(\Delta \mathrm{E}^{*}\right)$.

Table 6. Denture base resins at each time point in black tea $(n=10)$

\begin{tabular}{lcccc}
\hline & Day 0 & Day 5 & Day 10 & Day 15 \\
\hline Paladent 20 & 0 & 2.2 & 3.0 & 3.2 \\
SR Triplex Hot & 0 & 1.4 & 2.3 & 2.4 \\
QC-20 & 0 & 1.5 & 1.9 & 2.1 \\
\hline
\end{tabular}

Values are presented as mean color differences $\left(\Delta \mathrm{E}^{*}\right)$.

was used as the control group.

After coloration, each denture was immersed in distilled water for 24 hours before the first color measurement, and the color was measured on 5, 10, and 15 days after being deposited into each experimental solution. The sample dentures were cleansed with running water and a brush for 30 seconds, and the color was measured immediately after drying. The spectrophotometer (SP 62 PURELAB, Flex3, X-RITE) was zero calibrated for absorbance in the optical zone, followed by white calibration using a standard white reflector plate. Finally, the color was measured by attaching the denture close to the optical zone.

The experimental results of this study were analyzed using the IBM SPSS Statistics for ver. 19.0 (IBM Co., Armonk, NY, USA) statistical program. All data underwent repeated measures ANOVA test.

\section{Results}

The following results pertain to the color change measured over time using the spectrophotometer (SP 62 PURELAB Flex3, $\mathrm{X}$-RITE) after immersing the dentures in each experimental solution. Mean color differences seen in dentures exposed to distilled water were high in QC-20 (Dentsply Sirona), followed by SR Triplex Hot (Ivoclar Vivadent Inc.), and Paladent 20 (Heraeus Group) (Table 5).

Mean color differences seen in dentures exposed to black
Table 7. Denture base resins at each time point in coffee $(n=5)$

\begin{tabular}{lcccc}
\hline & Day 0 & Day 5 & Day 10 & Day 15 \\
\hline Paladent 20 & 0 & 2.0 & 2.0 & 2.7 \\
SR Triplex Hot & 0 & 2.0 & 2.0 & 2.7 \\
QC-20 & 0 & 1.2 & 1.3 & 1.7 \\
\hline
\end{tabular}

Values are presented as mean color differences $\left(\Delta \mathrm{E}^{*}\right)$.

tea were high in Paladent 20 (Heraeus Group), followed by SR Triplex Hot (Ivoclar Vivadent Inc.), and QC-20 (Dentsply Sirona) (Table 6).

Mean color differences seen in dentures exposed to coffee were high in SR Triplex Hot (Ivoclar Vivadent Inc.), followed by Paladent 20 (Heraeus Group), and QC-20 (Dentsply Sirona) (Table 7).

\section{Discussion}

Denture resin is used mainly for fixing and maintaining an artificial tooth, for compatibility with dentures, and for the recovery of tissues of residual tooth root. Extrinsic factors, such as denture cleansing solution, food, and saliva, as well as intrinsic factors, such as material ingredients and polymerizing method, can have an impact on the solidity and color stability of denture resin. To harmonize the denture resin within the oral cavity, the color should be transparent so that it reflects the natural teeth, or it should be identical to that of the natural teeth. However, the color of dentures is subject to change within the oral cavity as the temperature changes. Moreover, the substance is always soaked in saliva, and the $\mathrm{pH}$ changes immensely due to the ingredients of the food along with stress level and repeated loads [8,9]. Dentures should be made to endure mechanical intensity as well as coloring and discoloration.

According to Preston [10], the factors affecting the color of the material are object, observer, and source of light. Also, Esquivel et al. [11] stated that the color that an object expresses is affected by the physical characteristics of color, the nature of incident light reflected by the object, interaction with other colors, and subjective judgment of an observer.

Wendt [12] commented on the relationship between the degree of surface grinding and coloring and that the color stability is low on rough surfaces. Hence, in this study, the surface 
of the denture resin, related to discoloration, was ground to 800 grits. Khokhar et al. [13] reported in their study that to enhance the color stability of the resin, the viscosity should be decreased and wettability should be increased by lowering the water absorbance.

The authors hope that this study on color change will help in choosing the denture resin. If the denture resin can be actively studied and developed because of its superiority in mechanical and physical characteristics, it could be manufactured in such a way as to decrease air bubbles during the polymerization and water absorption depending on its density, thereby improving its aesthetic aspects. Moreover, other variables that are related to color change should be continuously observed and studied.

\section{Conclusion}

In this experiment, coffee and black tea, which Koreans frequently drink, and distilled water, which served as the control group, were used to evaluate their effects on the colors of denture acrylic resins of Paladent 20 (Heraeus Group), SR Triplex Hot (Ivoclar Vivadent Inc.), and QC-20 (Dentsply Sirona). all of which are frequently used materials to date. The results were as follows:

1. There was a difference over time $(\mathrm{p}=0.004)$, but no difference among the products $(\mathrm{p}=0.920)$.

2. QC-20 (Dentsply Sirona) and SR Triplex Hot (Ivoclar Vivadent Inc.) showed no significant difference in the result, both of which were of the general level of color stability when compared with other curing resins. Paladent 20 (Heraeus Group) showed inferior results in color stability when exposed to black tea.

3 . The degree of discoloration was severe in areas where polishing was insufficient in the total dentures.

Considering the above results, it is advisable to caution patients with dentures made of Paladent 20 (Heraeus Group) against drinking black tea habitually.

\section{Conflict of Interest}

No potential conflict of interest relevant to this article was reported.

\section{ORCID}

Seong-Hyuk Bang, https://orcid.org/0000-0003-1399-0878

So-Min Kim, https://orcid.org/0000-0003-1385-0322

\section{References}

1. Sweeney WT. Denture base material: acrylic resins. J Am Dent Assoc 1939;26:1863-73.

2. Powers JM, Sakaguchi RL. Craig's restorative dental materials. 12th ed. St. Louis: Mosby; 2006:513-39.

3. Hersek N, Canay S, Uzun G, Yildiz F. Color stability of denture base acrylic resins in three food colorants. J Prosthet Dent 1999; 81:375-9.

4. Phoenix RD. Denture base resins. In: Anusavice KJ, ed. Phillips' science of dental materials. 11th ed. St. Louis: Saunders; 2003: 721-56.

5. Asmussen E. An accelerated test for color stability of restorative resins. Acta Odontol Scand 1981;39:329-32.

6. Asmussen E. Factors affecting the color stability of restorative resins. Acta Odontol Scand 1983;41:11-8.

7. Buyukyilmaz S, Ruyter I. Color stability of denture base polymers. Int J Prosthodont 1994;7:372-82.

8. Wozniak WT, Muller TP, Silverman R, Moser JB. Photographic assessment of colour changes in cold and heat-cure resins. J Oral Rehabil 1981;8:333-9.

9. Fusayama T, Hirano T, Kono A. Discoloration test of acrylic resin fillings by an organic dye. J Prosthet Dent 1971;25:532-9.

10. Preston JD. Current status of shade selection and color matching. Quintessence Int 1985;16:47-58.

11. Esquivel JF, Chai J, Wozniak WT. Color stability of low-fusing porcelains for titanium. Int J Prosthodont 1995;8:479-85.

12. Wendt SL Jr. The effect of heat used as secondary cure upon the physical properties of three composite resins. II. Wear, hardness, and color stability. Quintessence Int 1987;18:351-6.

13. Khokhar ZA, Razzoog ME, Yaman P. Color stability of restorative resins. Quintessence Int 1991;22:733-7. 